\title{
Erweiterung des Treuhandpartnernetzes in Zürich
}

Die Walser \& Partner AG ist seit über 15 Jahren ein im In- und Ausland tätiges Dienstleistungsunternehmen in Zürich, Freienbach und Zug mit den Schwergewichten Gründungen, Rechnungswesen, Salärwesen, Steuerrecht und Unternehmensberatung. Die Leistungen werden durch das Zusammenwirken von Fachspezialisten aus den einzelnen Disziplinen und durch ein stabiles Netzwerk massgeblich geprägt.

Die Walser \& Partner AG ist Mitglied von Geneva Group International (GGI), dem 6. grössten internationalen Netzwerk etablierter unabhängiger Treuhand-, Anwalts-, Steuerberatungs- und Wirtschaftsprüfungskanzleien sowie Unternehmensberatungen.

Unternehmerisches Denken ist für die Walser \& Partner AG auch in der Arztpraxis von ausschlaggebender Bedeutung. Nur eine optimale Betreuung bietet dem Mandanten Gewähr, seinen wirtschaftlichen Erfolg sicherzustellen und zu optimieren. Die Stärken des neuen Partners sind Zuverlässigkeit, Professionalität und Kompetenz.

Die Walser \& Partner AG unterstützt Sie mit einem eingespielten Team von rund 10 Mitarbeitenden, um

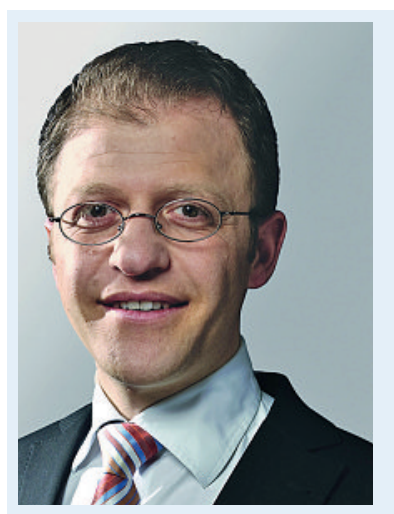

Abdullah Demir

Partner/Geschäftsführer

Eidg. dipl. Treuhandexperte

Abdullah Demir hat über 10 Jahre Berufserfahrung im Treuhandbereich. Er ist ein ausgewiesener Spezialist für sämtliche Treuhandfragen. Als Partner, Verwaltungsrat und Geschäftsführer der Walser \& Partner AG kennt er das Unternehmertum aus eigener Erfahrung.

abdullah.demir@fmhtreuhand.ch die besten Lösungen für Ihre Praxis, Gemeinschaftspraxis bzw. Unternehmung zu finden. Es werden sämtliche treuhänderischen Dienstleistungen angeboten:

- Einstieg in die Selbständigkeit

- Aufbau des Rechnungswesens

- Finanz-, Betriebs- und Lohnbuchhaltung

- Administration

- Steuerberatung

- Unternehmensberatung

Abdullah Demir und Michael Brändli sind Ihre FMH Treuhand Services-Ansprechpartner bei der Walser \& Partner AG. Sie freuen sich darauf, Ihr Unternehmen zusammen mit Ihnen in eine erfolgreiche Zukunft zu führen.

\section{Walser \& Partner AG Zürich FMH Treuhand Services}

Löwenstrasse 32

$\mathrm{CH}-8001$ Zürich

Tel. 05859612 62, Fax 0585961260

www.walserpartner.ch

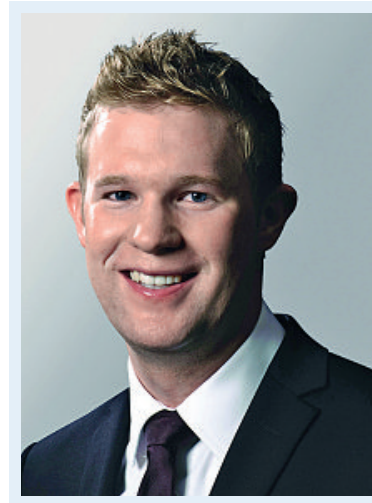

Michael Brändli

Sachbearbeiter Treuhand Student an der FH HWZ

Michael Brändli ist seit seiner Lehre im Treuhandbereich tätig. Während seiner 9-jährigen Tätigkeit im Treuhandbereich konnte er sich ein sehr gutes Wissen aneignen.

michael.braendli@fmhtreuhand.ch 